\title{
LA GRAN SULTANA DE MIGUEL DE CERVANTES: ADAPTACIÓN DEL TEXTO Y PUESTA EN ESCENA
}

Arrinconadas «en un cofre" y «consagradas al perpetuo silencio» dice Cervantes que quedaron sus comedias, pues no hallo, cuando a ellas volviera, "pájaros en los nidos de antaño", es decir, autor que se las pidiera ${ }^{1}$. Casi cuatrocientos años después de escribir esto, una de las obras de don Miguel llegó por vez primera a los escenarios y a fe que La Gran Sultana, como luego veremos, convenció a una audiencia que, seguimos parafraseando a Cervantes, hizo correr las alabanzas de un autor dramático, reducido en los escenarios durante siglos prácticamente a una tragedia, una o dos de sus comedias y, eso sí, un ramillete de entremeses ${ }^{2}$.

La Gran Sultana se estrenó en Sevilla el 6 de septiembre de 1992 por la Compañía Nacional de Teatro Clásico (CNTC) diri-

1 Miguel de Cervantes. Teatro completo. Edición, introducción y notas de Antonio Rey Hazas y Florencio Sevilla Arroyo, Barcelona, Planeta, 1987, p. 11.

2 Si ausente había estado de los escenarios, tampoco la crítica ha sido generosa con ella cuantitativamente hasta hace muy poco tiempo. En cuanto a la estima de los estudiosos que han llegado a la comedia, las opiniones han sido muy dispares. Vid. un resumen en mi trabajo «Cervantes, Constantinopla y La Gran Sultana*, en Anales Cervantinos, 31, 1993, pp. 201-213. Consúltense, además, como estudios recientes: PaUl Lewis SMITH, «La gran sultana Doña Catalina de Oviedo: A Cervantes Practical Joke», en Forum for Modern Language Studies, 1981, pp. 68-82; Jean Canavaggio, «Sobre lo cómico en el teatro cervantino: Tristán y Madrigal, bufones in partibus», en Nueva Revista de Filologia Hispánica, 34,1985-1986, pp. 538-547, publicado también en la parte correspondiente a la obra cervantina en Cuadernos de Teatro Clásico, 7, 1992, pp. 47 53; Francisco LOPEZ Estrada, «Vista a Oriente: la espafiola en Constantinopla*, en tdem, pp. 31-46; Stanislav Zimic, El teatro de Cervantes, Madrid, Castalia, 1993. pp. 183-203. 
gida -obra y Compañía - por Adolfo Marsillach, con escenografía de Carlos Cytrynowski y en versión de Luis Alberto de Cuenca. Era la primera obra cervantina llevada a escena por la CNTC y Marsillach justificaba así la elección: «A nosotros esta obra nos fascina [...] nos fascina por lo extraordinario del mundo que presenta, por el irónico romance amoroso de la pasión desbordada y enloquecida, por el desplante de una Constantinopla altiva y pasmosa, por el perfume de una civilización sensual y miniaturista y, sobre todo, porque este texto -este hermosísimo y refrescante texto- es un canto arrebatado a la tolerancian ${ }^{3}$.

Las páginas que siguen estarán dedicadas a un acercamiento a la adaptación de ese texto llevada a cabo por Luis Alberto de Cuenca, para, a continuación, analizar la recepción de esta puesta en escena de La Gran Sultana por parte de la crítica y del público ${ }^{4}$.

\section{LA ADAPTACIÓN DEL TEXTO}

Uno de los aspectos más controvertidos, referido al teatro clásico presente en los escenarios en los últimos años, es el de las adaptaciones de las obras de Lope, Calderón, Moreto, etc. La controversia, a la que nos hemos referido en otras ocasiones brevemente $^{5}$ y que ha merecido algunos recientes trabajos ${ }^{6}$, es-

3 Texto del Programa de mano y recogido en Cuadernos de teatro clásico, núm. 7, 1992, pp. 201-202. Vid,, en este volumen, además de una serie de articulos sobre el teatro de Cervantes y Cervantes en el teatro, amplia información en torno al montaje de la obra.

- Vid., como antecedentes de este trabajo, y en relación directa con él, Luciano García LORENZo, "El teatro clásico en la escena española actual», en La Comedia. Actas del seminario Hispano-Francés de la Casa de Valazquez. Madrid, Casa de Velázquez, 1994; del mismo, «La recepción del teatro clásico espafiol: El desdén con el desdén, de Agustín Moreto, y La verdad sospechosa, de Juan Ruiz de Alarcóns, en Revista de Literatura, 56, 1993, pp. 557-572. En estos trabajos remito a bibliografía anterior sobre los clásicos en la escena española última, aunque sin ser tan específica como la anteriormente citada.

5. "El teatro clásico español en escena (1976-1987)», en Insula, 492, 1987, 21-22.

- Vid. Francisco Ruiz Ramón, «Sobre la adaptación de un texto clásico», en Celebración y catarsis (Leer el teatro español). Murcia, Cuadernos de la Cátedra de la Universidad de Murcia, 1988; ENRIOUe Llovet, *Adaptaciones teatrales», en Boletín informativo. Fundación Juan March, 180, 1988, pp. 3-16; José RoMerA CAstillo, "La Celestina de Rojas/La Celestina de Torrente Ballestern, en Homenaje a Humberto Lopez Morales. Edición María Vaquero y Amparo Morales. Madrid, Arco Libros, 1991, pp. 265-283; del mismo, «El Alcalde de Zalamea de Calderón y Francisco Brines. (Dos signos en una serie semiótica)», en Homena- 
pera un estudio tan amplio como el tema merece y basado en el corpus adecuado, dejando de lado opiniones que tienen a veces como fundamento la visión única de un espectáculo, cuando no la influencia del nombre del adaptador. Las sorpresas, en el momento en que este trabajo se lleve a cabo, no serán pocas, tanto en los criterios tan diversos que se han tomado para realizar las adaptaciones, como en los resultados de los diferentes acercamientos.

Por lo que se refiere a la Compañía Nacional de Teatro Clásico, sabido es que las adaptaciones de los textos se han encargado, generalmente, a personas con experiencia en este trabajo (Juan Germán Shroeder), dramaturgos (José Luis Alonso de Santos), novelistas (Francisco Ayala), profesores (Francisco Rico), poetas (Claudio Rodríguez), etc., y ya desde los primeros pasos de la CNTC surgieron voces discrepantes, desde aquellos que consideraban que prácticamente no había que tocar a los textos (y más aún tratándose de una Compañía nacional) hasta los que reconocían que era necesario "limpiar» la escritura de los clásicos, pero sólo en aspectos mínimos y cuando lo requiriera la mejor comprensión de los versos de nuestros autores áureos.

Teniendo en cuenta, en primer lugar y como hemos afirmado, la escasez de trabajos sobre el tema $y$, por otra parte, la opinión casi generalizada en cuanto al respeto que se ha tenido por el texto cervantino a cargo de Luis Alberto de Cuenca (claro está, con la participación de Adolfo Marsillach, como Cuenca ha repetido en varias ocasiones) queremos realizar una aproximación a la adaptación de La Gran Sultana, ofreciendo muy explicitamente los cambios, añadidos, supresiones, etc., efectuados en la pieza cervantina. Insistimos en que se trata de una aproximación, dejando para otro momento el análisis y estudio de otros textos llevados a escena por la CNTC. Conste, pues, desde el principio, que el resultado surgido del análisis de las primeras secuencias de La Gran Sultana no debe extenderse, en absoluto, a lo que han sido, en mayor o menor medida, otras adaptaciones llevadas a cabo por la Compañía Nacional de Teatro Clásico. Del texto de El Caballero de Olmedo o La verdad sospechosa

je a Hans Flasche. Ed. de Karl-Hermann Körner und Günther Zimmermann, Stuttgart, Franz Steiner Verlag, 1991, pp. 174-186. Estos dos trabajos de Romera Castillo están ahora recogidos en su libro Frutos del mejor árbol. Estudios sobre el teatro español del Siglo de Oro. Madrid, UNED, pp. 195-233. Vid., también, las últimas páginas del estudio de ANTONIO SERrano, «El teatro del Siglo de Oro entre los anos 1985-1990», en En torno al teatro del Siglo de Oro. Jomadas VII-VIII. Almeria, Diputación de Almeria-Instituto de Estudios almerienses, 1992, pp. 183-198. 
escuchado por los espectadores al que también tuvieron ocasion de atender con El Burlador de Sevilla o El Jardín de Falerina hay considerable distancia, como otro tipo de acercamiento exige el paso concreto a la escena de una obra como La Celestina, y así lo entendió Gonzalo Torrente Ballester?

Aunque el fragmento sea un tanto extenso, véanse los cambios llevados a cabo en los primeros 300 versos de la comedia cervantina. La primera columna corresponde al texto de Cervantes y la segunda a la adaptación de Luis Alberto de Cuenca. Figuran en cursiva las alteraciones y hemos dejado el hueco correspondiente para los versos suprimidos ${ }^{8}$.

\section{LA GRAN SULTANA JORNADA PRIMERA}

[Sale[n] SNLEC, turco, y ROBERTO, vestido a lo griego, y, detrás dellos, un ALiraBe vestido de un alquicel; tray en une lanze muchas estopas, y en una varilla de membrillo, en la punta, un papel como billete, y una velitla de cera encendida en la mano; este tal ALARABE se pone al lado del teatro, sin hablar palabra, y luego dice RoBerTo:)

ROBERTO. La pompa y majestad deste tirano, sin duda alguna, sube y se engrandece sobre las fuerzas del poder humano. Mas ¿qué fanstama es esta que se ofrece, coronada de estopas media lanza? Alárabe en el traje me parece.

SAlEC. Tienen aquí los pobres esta usanza cuando alguno a pedir justicia viene: que sólo el interés es quien la alcanza. De una caña y de estopas se previene, y cuando el turco pasa enciende fuego, a cuyo esplendor êl se detiene; pide justicia a voces, dale luego lugar la guarda, y el pobre, como jara, arremete turbado y sin sosiego, y en la punta y remate de una vara al gran seĩor su memorial presenta, que para aquel efecto el paso para. Luego, a un bello garzón, que tiene cuenta con estos memoriales, se le entrega, que, en relación, después dellos da cuenta; pero jamás el termino se llega del buen despacho destos miserables, que el interts le turba y se le niega.

ROBERTO. Cosas he visto aquil que de admirables
(Salen SAlEC, turco, y ROBERTo, vestido a lo griego, y, detrás dellos, un ALARABE vestido de un alquicel; tray en una lanza muchas estopes, y en une varilla de membrillo, en la punta, un papel como billete, y una velilla de cera encendida en la mano; este tal ALARABE se pone al ledo del teatro, sin hablar palabra, y luego dice ROBERTo:)

ROBERTO. La pompa y majestad de este tirano, sube, sin duda alguna, y se engrandece sobre las fuerzas del poder humano. Mas iqué fanstama es este que se ofrece, con estopas prendidas en la lanze? Alárabe en el traje me parece.

SAlEC. Tienen aquf los pobres esta usanza cuando alguno a pedir justicia viene: aunque es raro el dichoso que la alcanza. De una caria y de estopas se previene, y cuando el turco pasa enciende fuego. a cuyo resplandor él se detiene; pide justicia a voces, dale luego lugar la guardia; el pobre no se azara, arremete turbado y sin sosiego, y en la punta y remate de una vara al gran señor su memorial presenta, que para aquel efecto el paso para. Luego, a un bello garión, que lleva cuenta de tales memoriales, se lo entrega, y el en su lista lo pedido asienta; pero jamás el término les llega de sus pesares a estos miserables, pues todo lo que piden se les niega.

7 Vid. el Prólogo que puso a su adaptación: Fernando de Rojas. La Celestina. Madrid, Ministerio de Cultura, INAEM-CNTC [1988], pp. 3-7.

- Seguimos la edición de Rey-Sevilla, ya citada, pp. 373-381. La adaptación está publicada por el Ministerio de Cultura, 1992. Los versos que nos interesan, en pp. 13-25. 
pueden al más gallardo entendimiento suspender.

SALEC. Verás otras más notables. Ya está a pie el gran señor, puedes atento verle a tu gusto, que el cristiano puede mirarle rostro a rostro a su contento. A ningún moro o turco se concede que levante los ojos a miralle, y en esto a toda majestad excede.

(Entra en este instante el Grun Turco con mucho acompañamiento; delante de si lleva un PNE vestido a lo turquesco, con una flecha en la mano, levantada en alto, y detrás del Turco van otros dos GARZONES con dos bolsas de terciopelo verde. donde ponen los papeles que el Turco les da.)

ROBERTO. Por cierto, el es mancebo de buen talle, y que, de gravedad y bizarria, la fama, con razón, puede loalle.

SALEC, Hoy hace la zalá en Santa Sofía, ese templo que ves, que en la grandeza excede a cuantos tiene la Turquia.

ROBERTO. A encender y a gritar el moro empieza; el Turco se detiene mesurado, señal de piedad como de alteza. El moro llega; un memorial le ha dado: el gran señor le toma y se le entrega a un bel garzón que casi trai al lado.

ROBERTO. A encender y a gritar el moro empiez

el Turco se detiene mesurado,

señal de piedad como de alteza.

El moro llega; un memorial le ha dado; el gran señor lo toma y se lo entrega a ese garzón que casi trae al lado.

(En tanto que esto dice RoBerto y el TURCo pasa, tiene SALEC doblado el cuerpo y inclinada la cabeza, sin miralle al rostro.)

SAlEC. Esta audiencia al que es pobre no se niega. ¿Podré alzar la cabeza?

ROBERTO. Alza y mira, que ya el Señor a la mezquita llega, cuya grandeza desde aquí se admira.

(Éntrase el GRan SENOR, y queda[n] en el teatro SALEC $Y$ ROBERTO.)

SAlEC. ¿Qué te parece, Roberto, de la pompa y majestad que aquí se te ha descubierto?

RoBerto. Que no creo a la verdad, y pongo duda en lo cierto.

SuIEC. De a pie y de a caballo, van seis mil soldados.

ROBERTO. Si irán.

SALEC. No hay que dudar, que seis mil son.

ROBERTo. Juntamente, admiración y gusto y asombro dan.

SALEC. Cuando sale a la zalá sale con este decoro;
SAlEC. ¿Qué te parece, Roberto de la pompa y majestad que aquil se te ha descubierto?

ROBERTO. Que no creo a la verdad, y pongo duda en lo cierto.

SALEC. De a pie y de a caballo, van seis mil soldados.

ROBERTO. Si irán.

SALEC. No hay que dudar: que seis mil son.

ROBERTO. Juntamente, admiración y gusto $y$ asombro dan.

60

Cuando sale a la zalá
SAlEC. Esta audiencia al que es pobre no se niega.

ROBERTO. Salec, ffiate y mira, que ya el Señor a la mezquita llega, cuya grandeza desde aquí se admira.

(Éntrase el GRIN SENOR, y queda[n] en el teatro SALEC $Y$ ROBERT0.)

sale con este decoro; 
y es el día del xumá, que asi el viernes llama el moro.

RoBerto. BBien acompañado va! Pero, pues nos da lugar el tiempo, quiero acabar de contarte lo que ayer comence a darte a entender.

Sulec. Vuelve, amigo, a comenzar.

RoBerTo. Aquel mancebo que dije vengo a buscar: que le quiero más que al alma por quien vivo. más que a los ojos que tengo.

Desde su pequeña edad

fui su ayo y su maestro. y del templo de la fama le ensené el camino estrecho: encaminele los pasos por el angosto sendero de la virtud; tuve a raya sus juveniles deseos; pero no fueron bastantes mis bien mirados consejos, mis prevenciones cristianas, del bien y mal mil ejemplos, para que, en mitad del curso de su más florido tiempo, amor no se le saltease. monfí de los atios tiernos. Enamoróse de Clara, La hija de aquel Lamberto que tú en Praga conociste, teutonico caballero.

Sus padres y su hermosura nombre de Clara la dieron; pero quizá sus desdichas en escuridad la han puesto. Demandóla por esposa, y no salio con su intento; no porque no fuese igual y acertado el casamiento, sino porque las desgracias treen su corriente de lejos, y no hay diligencia humana que prevenge su remedio. Finalmente, ell la sacó: que voluntades que han puesto la mina en cumplir su gusto, pierden respetos y miedos. Solos y a pie, en una noche de las frias del inviemo, iban los pobres amantes, sin saber adonde, huyendo; y es el día del xumá, que asi el viernes llama el moro.

Roserto. [Bien acompanado va! Pero, pues nos da lugar el tiempo, quiero acabar de contarte lo que ayer comenct a darte a entender.

SAlEC. Vuelve, amigo, a comenzar.

RoBerto. Aquel mancebo que dije vengo a buscar: que le quiero más que al alma por quien vivo, más que a los ojos que tengo. Desde su pequeña edad fui su ayo y su maestro, y del templo de la fama le enserié el camino estrecho; pretendi guiar sus pasos por el angosto sendero de la virtud; tuve a raya sus juveniles deseos; pero no fueron bastantes mis bien mirados consejos, mis prevenciones cristianas, del bien y mal mil ejemplos, para que, en mitad del curso de su más florido tiempo, amor no se le saltease, ladrón de los años tiernos. Enamoróse de Clara, la hija de aquel Valerio que tú en Praga conociste, gela y flor de caballeros. Sus padres y su hermosura nombre de Clara la dieron; pero quizás sus desdichas en oscuridad la han puesto. Pidió a Clara por esposa, y no salio con su intento; no porque no fuese igual y acertado el casamiento, sino porque las desgracias traen su corriente de lejos, y no hay diligencia humana que prevenga su remedio. Finalmente, le repto: que voluntades que han puesto la mira en cumplir su gusto, pierden respetos y miedos. Solos y a pie, en una noche 
y, al tiempo que ya yo habia

echado a Lamberto menos,

que este [es] el nombre del triste

que he dicho que a buscar vengo

con aliento desmayado,

de un frío sudor cubierto

el rostro, y todo turbado

ante mis ojos le veo.

Arrojoseme a los pies,

la color como de un muerto,

$y$, con voz interrumpida

de sollozos, dijo: eMuero,

padre y señor, que estos nombres

a tus obras se los debo.

A Clara llevan cautiva

los turcos de Rocaferro.

Yo, cobarde; yo, mezquino

y un traidor, que no lo niego,

hela dejado en sus manos

por tener los pies ligeros.

Esta noche la llevaba

no sé adónde, aunque sé cierto

que, si fortuna quisien,

futramos los dos al Cielo.,

A la nueva triste y nueva,

en un confuso silencio

quede, sin osar decirle:

sHijo mío, ¿cómo es esto?,

De aquesta perplejidad

me sacó el marcial estruendo

del rebato a que tocaron

las companas en el pueblo.

Púseme luego a caballo.

salió conmigo Lamberto

en otro, y salio una tropa

de caballos herreruelos.

Con la escuridad, perdimos

el rastro de los que hicieron

el robo de Clara, y otros

que con el día se vieron.

Temerosos de celada.

no nos apartamos lejos

del lugar, al cual volvimos

cansados y sin Lamberto.

Sulec. Pues ¿cómo? ¿Quedose aposta?

Roserto. Aposta, a lo que sospecho, porque nunca ha parecido desde entonces, vivo o muerto. Su padre ofreció por Clan gran cantidad de dinero, pero no le fue posible cobrarla por ningún precio. y, al tiempo que yo hube echado

de menos a mi Lamberto,

que éste [es] el nombre del triste

que be dicho que a buscar vengo

con aliento desmayado,

de un frío sudor cubierto

el rostro, y todo turbado

ante mis ojos le veo.

Arrojóseme a los pies,

la color como de un muerto,

$y$, con voz internumpida

de sollozos, dijo: Muero,

padre y señor, que estos nombres

2 tus obras se los debo.

A Clara llevan cautiva

los turcos de Rocaferro.

Yo, cobarde; yo, mezquino

y un traidor, que no lo niego,

hela dejado en sus manos

por tener los pies ligeros.

Esta noche la llevaba

no sé adónde, aunque sé cierto

que, si fortuna quisiera,

fuéramos los dos al Cielo.

$A$ la nueva triste y grave,

en un confuso silencio

quede, sin osar decirle:

-Hijo mío, ¿cómo es esto?,

De esa gran perplejidad

me sacó el marcial estruendo

del rebato a que tocaron

las companas en el pueblo.

Púseme luego a caballo,

montó esimismo Lamberto

en otro, y salió una tropa

de soldados detrís nuesiro.

Con la oscurided, perdimos

el rastro de los que hicieron

el robo de Clara, y otros

que con el día se vieron.

Temerosos de celada,

no nos apartamos lejos

del lugar, al cual volvimos

cansados y sin Lamberto.

SALEC. Pues ¿cómo? ¿Quedose aposta?

RoBerto. Aposta, a lo que sospecho, porque nunca ha parecido desde entonces, vivo o muerto.

Su padre ofrecio por Clare gran cantidad de dinero, pero no le fue posible cobrarla por ningún precio. 
Dijose por cosa cierta que el turco que fue su duefio la presentó al gran setior por ser hermose en extremo. Por saber si esto es verdad y por saber de Lamberto be venido como has visto aqui en hábito de griego. Sé hablar la lengua de modo que pasar por griego entiendo.

SLIEC. Puesto que nunca la sepas, no tienes de qué haber miedo: aquí todo es confusión y todos nos entendemos con una lengua mezclada que ignoramos y sabemos. De mi no te escaparás, pues cuando te vi, al momento te conoci.

Roвerto. ¡Gran memoria!

SALEC. Siempre la ture en extremo.

Roserto. Pues icómo te has olvidado de quién eres?

SNiec. No hablemos en eso agora; otro dia de mis cosas trataremos: que, si va a decir verdad, yo ninguna cosa creo.

Roberto. Fino ateista te muestras.

SULEC. Yo no sé lo que me muestro; solo se que he de mostrarte. con obres al descubierto, que soy tu amigo, a la traza como lo fui en algún tiempo; y para saber de Clara, un eunuco del gobierno del serrallo del Gran Turco podrá hacerme satisfecho, que es mi amigo. Y, entre tanto, puedes mirar por Lamberto: quizá, como tuvo el alma, tambien tendrá preso el cuerpo.

(Entranse. Salen Muwt y Rustan, eumucos.)

Mumi. Ten, Rustán, la lengua muda, y conmigo no autorices tu fee, de verdad desnuda, pues mientes en cunnto dices, y eres cristiano, sin duda: que el tener ansi encerrada tanto tiempo y tan guardada
Dijose por cosa cierta

que el ladnón que fue su duetio la presentó al Gran Turco por ser bermosa en extremo. Por saber si esto es verdad y por saber de lamberto he venido como has visto aqui en hábito de griego. Sé hablar la lengua de modo que pasar por griego puedo.

SuLEC. Aunque hablarla no supieras, no tienes de qué haber miedo: aquí todo es confusión y todos nos entendemos en una lengua mezclada que ignoramos y sabemos. Pero a mi no me engariaste, pues cuando te vi, al momento te conoci.

RoBerto. ¡Gran memoria!

SALEC. Siempre la tuve en extremo.

Roserto. Pues icómo te has olvidado de quien eres?

SNLEC. No hablemos en eso ahora; otro dia de mis cosas trataremos: que, si digo la verdad, yo ninguna cosa creo.

ROBerto. Muy incredulo te muestras,

Sulec. Yo no sé lo que me muestro; solo sé que he de mostrarte. con obras al descubierto, que soy tu amigo, del modo como lo fuere otro tiempo; y para saber de Clarn, un eunuco del gobiemo del serrallo del Gran Turco podrá decime en secreto, que he sido de su beldad. Busca, mientras, a Lamberto: quizá, como tuvo el alma, también tendré preso el cuerpo.

(Entranse. Salen Musi y RUSTiN, eunucos.)

Mnut. Ten, Rustín, la lengua muda, y no defiendas tu fe, que está de verdad desnuda. Por lo que has dicho y se ve y eres cristiano, sin duda: que el tener est encerrada tanto tiempo y tan guardada 
a la cautiva espaniola, es seital bastante y sola que tu intención es dañada. Has quitado al gran setior de gozar la hermosura que tiene el mundo mayor, siendo mal darle madura fruta, que verde es mejor. Seis anos ha que la celas y la encubres con cautelas que ya no pueden durar, y agora por desvelar esta verdad te desvelas. Pero jespera, perro, aguarda, y verás de qué manera la fe al gran sehor se guarda!

RustiN. ¡Mami amigo, espera, espera!

Munt. Llega el castigo, aunque tarda; y el que sabe una traición, y se estŕ sin descubrilla algún tiempo, da ocasión de pensar si en consentilla tuvo parte en la intención. La tuya he sabido hoy, y asi, al gran seîor me voy a contarle tu maldad.

\section{(Éntrase Muvi.)}

Rust/N. No hay negalle esta verdad; por empalado me doy.

(Sak Donu Cataunu dE Oviedo, gran sultane, vestida a la turquesca.)

Sultaku. Rustín, ¿que hay?

MustiN.
de nuestra temprana muerte
es ya llegada la hora:
que asi el alma me lo advierte,
pues en mi costancia llora;
que, aunque parezco mujer,
nunca suelo yo verter
Kegrimas que den seijal
de grande bien o gran mal,
como suele acontecer.
Mami, setiora, ba notado,
con astucia y con maldad,
el tiempo que te he guardado,
y ha juzqado mi lealtad
por traición y por pecado.
Al gran seior va derecho
a contar por malo el hecho
que yo be tenido por bueno,

a la cautiva espanola, es señal bastante y sola que tu intención es malvado. Has privado al gran seitor de gozar la hermosura que tiene el mundo mayor, siendo mal darle madura fruta, que verde es mejor. Seis años ha que la celas y la encubres con cautelas que ya no pueden durar, y ahore por desvelar yo la verdad te desvelas. Pero jespera, perro, aguarda. y verós de qué manera la fe al gran señor se guarda!

Rustín. ¡Mamí amigo, espera, espera!

Muxt. Llega el castigo, aunque tarda; y el que sabe una traición, y se está sin descubrilla algún tiempo, da ocasión de pensar si en consentilla fue, en realidad, su intención. La tuya be sabido hoy, y asi, al gran seîor me voy a contarte tu maldad.

\section{(Entrase Maut.)}

RUSTiN. No hay negarle esta verdad; por empalado me doy.

(Sale DoRa Cataluna de OVtedo, gran suliana, vestide a la turquesca.)

Surtanu. ¿Qué ha habido, Rustán?

RUSTíN.

de nuestra temprana muerte es ya llegada la hora:

Asi el alma me lo advierte, pues, triste, suspire y llora; que, aunque parezca mujer, nunca suelo yo verter lágrimas que den seital de grande bien o grande mal, como otros suelen hacer. Mami, setion, ha notado, con astucia y con maldad, el tiempo que te he guardado, y ha juzgado mi lealtad por traición y por pecado. Al gran señor va derecho de malicia y rabia lleno su siempre maligno pecho,

Señora, 
de malicia y rabia lleno el siempre maligno pecha

Sultans. ¿Oué bemos de hacer?

RUSTAN. Esperar

la muerte con la entereza que se puede imaginar; aunque sé que a tu belleza sultan ha de respetar.

No te matará sultán; quien muera será Rustán, como deste caso autor.

Sultana. ¿Es cruel el gran señor?

RustiN. Nombre de blando le dan: pero, en efecto, es tirano.

Sultana. Con todo, confío en Dios, que su poderosa mano ha de librar a los dos deste temor, que no es vano; y si estuvieren cerrados los cielos por mis pecados, por no olr mi peticion, dispondré mi corazon - casos más desastrados. No triunfará el inhumano del alma; del cuerpo, si, caduco, trágil y vano.

RustiN. Este suceso temí de mi proceder cristiano. Mas no estoy arrepentido; antes estoy prevenido de paciencia y sufrimiento para cualquiera tormento.

Sultuna. Con mi intención has venido. Dispuesta estoy a tener por regalo cualquier pena que me pueda suceder.

Rustik. Nunca a muerte se condena tan gallardo parecer.

Hallaris en tu hermosun, no pena, sino ventura; yo, por el contrario extremo, hallart, como lo temo, en el fuego sepultur.
Sultask. ¿Que bemos de hacer?

Rustan.

la muerte con la entereza que se puede imaginar: aunque sé que a tu belleza tu ducio va a respetar. No te matará sultán; quien muera será Rustán, como deste caso autor.

Sultava. ¿Es cruel el gran señor?

RustiN. Nombre de blando le dan; pero, en efecto, es tirano.

Sultana. Con todo, confío en Dios, que su poderosa mano ha de librar a los dos deste temor, que no es vano;

Sultana. Con ese idea he venido. Dispuesta estoy a tener por regalo cualquier pena que me pueda suceder.

Rustik. Nunca a muerte se condena si es hermosa, a una mujer. Hallarés en tu hermosura, no pena, sino ventura; yo, por el contrario extremo, hallare, como to temo, en el fuego sepultura. 
Veamos, a continuación, un resumen de los cambios llevados a cabo en estos versos. Ofrecemos los datos sin tener en cuenta la importancia de los mismos - que la hay, y considerable-, sino siguiendo el orden en que van apareciendo en el texto:

1. Modernización de la grafía sin relevancia fonética, resolución de las abreviaturas, etc. (primera acotación, v. 45, v. 97, etc.).

2. Alteración de la sintaxis con el fin de lograr mayor claridad del texto (v. 2, etc.).

3. Cambio de género de palabras (v. 4).

4. Cambio de algún o algunos términos en una frase por evidente arcaísmo, cultismo, extranjerismo, etc. (vv. 5, 9, 12, 14, $19,20,22-23,24$, etc.).

5. Corrección de leísmo (vv. 20, 44).

6. Cambio de todos los términos de una frase (v. 21).

7. Supresión de acotación que indica movimiento del personaje, gesto, etc., pero no alude a la escenografía (acotación entre vv. 45-46).

8. Cambio de frase con cambio de sentido (v. 47, vv. 284-285...).

9. Adición de un término que exige la sintaxis actual y alteración de la frase con supresión de otro término (v. 57).

10. Cambio del nombre de un personaje al que sólo se alude en la obra con el fin de evitar equívocos, dado que es el nombre de otro personaje de la pieza (v. 91).

11. Cambio de término con el fin de evitar repetición de palabras excesivamente cercanas (v. 138, vv. 147-148).

12. Cambio de tiempo verbal (v. 246).

13. Alteración en el orden de los versos, pero sin sustitución de palabras en ninguno de ellos (vv. 257-260).

14. Supresión de versos (vv. 276-280).

Como se puede apreciar, los cambios efectuados en estos 300 versos de La Gran Sultana no son pocos (y repetimos que se considera una de las obras menos «tocadas» de las que se han llevado a escena por la (NTC), pero no afectan en absoluto al sentido de la pieza. Se podrá, a partir de esta afirmación, discutir la mayor o menor necesidad de alguno o algunos de esos cambios o supresiones, se estará o no de acuerdo con el resultado estético (no hablamos ahora de eficacia dramática, aunque tampoco debe olvidarse) de, también, alguno o algunos de esos cambios, pero lo que nos ofrece parece evidente es que, al menos por lo que respecta a La Gran Sultana, no llaman la atención negativamente las alteraciones llevadas a cabo por su adaptador e incluso, en algún momento, creemos muy oportuno ofre- 
cer al espectador un término para él comprensible en lugar de otro desaparecido de su bagaje lingúístico. Es más, estimamos que la obra cervantina no se siente maltratada por alterar en ciertos momentos el orden sintáctico de algunas frases, cuando su sentido sigue siendo exactamente el mismo y va a ser, desde el punto de vista dramático, es decir, lo que el espectador va a escuchar (no estamos hablando de lectura individual), mucho más adecuado en el escenario y recitado por unos actores en un momento y en un espacio que deben tenerse en cuenta, que obligan a que se tengan en cuenta.

Naturalmente, todas las afirmaciones anteriores, repetimos, las hacemos desde un supuesto: un texto sólo debe ser "tocado" cuando sea necesario. Y no nos detenemos en el cambio de sentido que puede sufrir la obra debido a algún cambio o alteración, porque éste es un principio para nosotros fuera de toda discusión.

\section{La Recepción de la Gran Sultana}

Siguiendo la metodología empleada en trabajos anteriores ya citados, intentamos en las páginas siguientes llegar a saber cuál ha sido la acogida de la comedia de Cervantes tanto por parte de la crítica como del público.

Por lo que se refiere a la crítica, fundamentalmente de la prensa diaria, comenzamos por la de Sevilla, lugar donde se estrenó la obra. Bajo el título muy significativo de «Una joya convertida en bisuterían, J. M. Padilla (Diario 16 de Andalucía, 8IX-1992) escribe una reseña absolutamente negativa para el espectáculo. Comienza con dos actores como Héctor Colomé y Arturo Querejeta de los que afirma: «Su portensosa voz [la de Héctor Colomé] recubre cualquier escena, pero sus dichos son mayestáticos, solemnes y huecos, porque se sirve del papel para lucir su cacofonía, evitando la laxitud que su trabajo requiere. Así le acompaña Arturo Querejeta, cuyo trabajo resulta tan plano como inapreciable». Y continúa Padilla inmediatamente: $\alpha$ Estos dos intérpretes marean por arriba y abajo de un escenario al mejor estilo de los pastelitos del barroco, relleno de luces, malvas y rosas, humos y olores. Una reconstrucción de teatrinos de cartón en su más pura concepción plástica, mediante múltiples trastos y practicables de gran resultado visual». Y continúa con buena dosis de ironía o, más bien, de sarcasmo: «Las escenas quedan muy monas, muy encantadoras. Y las ropitas de moros 
muy lindas...». Recuerda Padilla «los dineros» de la Compañía Nacional de Teatro Clásico, el mal hacer de los dos protagonistas (Manuel Navarro dice los versos «como un vulgar arriero", Silvia Marsó mantiene «actitudes histéricas», José Lifante encarna al Gran Cadí como "un betunero"), para dedicar las últimas líneas a Adolfo Marsillach con el mismo o mayor tono sarcástico que a los ya citados.

En El Correo de Andalucía (8-IX-1992) firma la reseña del estreno Jesús Vigorra, al cual parece no gustarle, ya de entrada, la obra cervantina en la que ve mucha «simpleza»; recuerda también, y en plural, los "muchos dineros» de la Compañía de Teatro Clásico, destaca "la armonía y belleza del espectáculon, la música pero no la coreografía, recuerda positivamente a Héctor Colomé en su papel de Madrigal y reconoce que el éxito del estreno se repetirá en cualquier lugar, "por el encanto de los trajes, por la seducción que ejerce sobre nosotros esta ritualidad oriental siempre soñada, expresada aquí sin estridencias, aunque con cierta obsesión por la huerta de Valencia. La caja mágica en la que se ha convertido el escenario que va dejando aparecer retazos de la imaginada Constantinopla, recuerda un inmenso bodegón de casa real con toda la fruta del paraíso». De nuevo, una manifiesta ironía cierra esta crónica, al anticipar que con este espectáculo se volverá a atraer a los espectadores que dejaron de ir al teatro después de "El diluvio que viene».

De diferente tono y mucho más positiva es la reseña de Joan de Sagarra (El País, 8-IX-1994). Destaca Sagarra que la CNTC haya remediado la «lamentable y vergonzante negligencia» de que La Gran Sultana no se hubiera estrenado hasta ese momento; señala que no está de acuerdo con la interpretación de "tolerancia” que Marsillach ha visto en la obra cervantina y ha pretendido manifestar a través de su puesta en escena, para resumir al final: «La Compañía Nacional de Teatro Clásico ha hecho de La gran sultana cervantina un espectáculo condenado al éxito. Un éxito del que es en gran parte responsable el trabajo de Cytrynowski, con su engolosinada escenografía, y la presencia de Héctor Colomé en el personaje del gracioso Madrigal que el actor argentino interpreta espléndidamente. Un éxito que el público sevillano refrendó con sus innumerables aplausos, aplausos que se acrecentaron cuando Marsillach salió a saludar, haciendo que todo el teatro se levantase de sus asientos».

Ya en Madrid, las opiniones de los críticos de esta ciudad fueron las que resumimos a continuación. Enrique Centeno, en la edición nacional de Diario 16 (24-IX-1992), resaltó el carácter festivo y de ajuego escénico permanente» que Adolfo Marsillach, 
según Centeno, había elegido para su montaje; destacó también el crítico la versión de Luis Alberto de Cuenca, para resumir: «Pero lo que de verdad importa en esta comedia es el juego, el enredo, la farsa. El resultado, una fiesta más de las que Marsillach ofrece desde su CNTC a un público que busca, por encima de todo, el hecho escénico vivo, la reflexión, el guiño, la diversión en sumax.

Comienza su crónica Javier Villán en el diario El Mundo (25IX-1992) así: «Bien podría aplicarse a este espectáculo un verso de Madrigal, personaje en el que pueden reconocerse algunos rasgos de Cervantes. El cautivo dice que, a su vuelta, contará peripecias que ha vivido "sin discrepar de la verdad un punto". Sin discrepancias, al menos demasiado evidentes, ha abordado Marsillach un texto cervantino que es un limpio y refrescante juego. Los versos de La Sultana son un verdadero gozo. Y como tal, como juego y fiesta, se derraman sobre el escenario, aunque a veces salgan trompicados. Y como fiesta acaba la función. Apoteosis». Y continúa destacando otras bondades del montaje, mérito de MarsiHach como director y de Cytrynowski como creador de las virtudes plásticas del mismo.

No es muy positiva la crónica que firma Lorenzo López Sancho en el $A B C$ (24-IX-1992). La escenografía es "como de festival», Marsillach ha movido los personajes «en el mismo sentido, o sea acentuando lo. pintoresco, lo cómico, la dicción intencionadamente rengloneada de los actores, no como habitual defecto del mal modo de decir el verso, que predomina desde que los más de los actores han renunciado a aprender cómo se ha de hacer...n. Afirma luego que la Constantinopla puesta en escena por Cytrynowski es más una revista musical que la imaginada por Cervantes, y acaba: «Cumple con su carácter festivo esta "gran Sultana" tardocervantina sevillana y matritense. Sin más».

Eduardo Haro Tecglen dedica su atención al estreno de la obra en Madrid y de ahí su reseña en El País (25-IX-1992), cargada de cierta ironía, pero sin el tono de la de J. M. Padilla citada antes. Dice del montaje Haro Tecglen: "Ahora la obra está limpita por un bonito decorado de, claro, Cytrynowski, que tiene también la hegemonía de este teatro con Marsillach, y que la merece algunas veces: colorista, inventor, exagerado en los trajes elegantes y pesados; vivo en los juegos de luz, sorprendente en las trampillas, y muy colaborador de las invenciones de Adolfo, que van con su temperamento irónico y gracioso, nada ajeno al que puso Cervantes». Remite a la crítica de Sagarra para otros aspectos del espectáculo y cierra su trabajo con una cierta carga de profundidad: a... tuvo también sus 15 minutos de aplausos, o 
más, y sus aclamaciones de entusiasmo. Faltó la salida a hombros de Marsillach, como pasó en el Apolo con el director de Los miserables: hubiera sido interesante de ver".

Comienza Alberto de la Hera su reseña en Ya (3-X-1992) con estas palabras: "He criticado muchas veces que el Estado destine sumas astronómicas al teatro oficial, mientras mantiene en crisis, en la indigencia, al teatro privado. Pero se pueden hacer excepciones. Es decir, hay casos en que el dinero oficial está muy bien empleado. Así sucede con La Gran Sultana, puesta en escena por la Compañía Nacional de Teatro Clásico». Destaca luego como "magníficos escenografía y vestuario", señala como excelente la interpretación por toda la compañía, aunque acota: "Tal vez, la protagonista, Silvia Marsó, debiera revisar su actuación para darle mayor peso, para restarle frivolidad e infantilismo». Y resume De la Hera: "La obra cae bien. Es entretenida. Es agradable de ver. Hace pasar un muy buen rato y paladear el teatro clásico [...] La Gran Sultana podrá representarse, y deberá representarse durante mucho tiempo, como un hermoso logro escénico".

Javier Vallejo señala en El Público (11-X-1992) el acierto de programar esta obra y, refiriéndose ya al montaje de la CNTC, dice: "Marsillach apoya su trabajo en el pintoresquismo del lugar y de las situaciones, con el soporte de una lúcida, llameante escenografía de Carlos Cytrynowski, que recrea el color y el esplendor del serrallo y que resuelve satisfactoriamente los diferentes lugares de la acción...". Se detiene luego en actores, música, etc., en general positivamente, para finalizar: «Una producción que, en líneas generales, mantiene la buena calidad media y el tono que son característicos en esta compañía».

Blanco y Negro dedicó dos páginas (11 y 18-X-1992) de las habituales de Fernando Lázaro Carreter para analizar la obra cervantina y el montaje de la CNTC. Después de detenerse en algunos aspectos del texto de don Miguel con su habitual maestría, el hoy director de la Real Academia de la Lengua dice al final de su trabajo: "La Compañía Nacional se ha apuntado un buen éxito. Y aplaudo fuerte».

En fin, recogemos una más de las críticas que aparecieron a raíz del estreno de La Gran Sultana y, en este caso, la firmada por Jerónimo López Mozo en Reseña (11-X-1992). Subraya este crítico y autor teatral el acierto de programar esta comedia, que logrará familiarizar al público con el teatro clásico; menciona el talante festivo impreso al espectáculo, aunque no tan inocente como puede parecer en un primer acercamiento, y cierra, en esta línea, sus afirmaciones con estas palabras: "hay como una vo- 
luntad, consecuente con la orientación del espectáculo, de sacar a la luz toda la comicidad que encierra el texto. Tal afán perjudica, a veces, su comprensión. Así es, aunque no debierax.

Pasemos, después de estos resúmenes, a las conclusiones que nos parecen más evidentes:

1. Como ya señalábamos en trabajos anteriores ${ }^{9}$, las discrepancias entre los críticos siguen siendo patentes. La Gran Sultana recibe críticas negativas en los periódicos sevillanos (en uno de ellos absolutamente negativa) cuando se estrena en esa ciudad y, sin ser muy elogiosa, sí, al menos, destaca alguna de sus bondades Joan de Sagarra en el periódico El País. Al presentarse la obra en Madrid, la situación cambiará, pues, aun cuando hay opiniones como la de Lorenzo López Sancho en $A B C$ poco complaciente, la mayor parte de los críticos destaca positivamente el montaje de la comedia e incluso alguno de ellos (Lázaro Carreter, De la Hera, Vallejo) están muy a favor de la puesta en escena de Marsillach.

2. La escenografía también recibe opiniones dispares: magnífica, acertada, etc., es para Alberto de la Hera, Sagarra, Villán, Vallejo... A Jesús Vigorra pareció no gustarle en absoluto, bastante reticente es Padilla ante ella y Lorenzo López Sancho la tacha de decorado "de festival» y «de revista musical "...

3. Hay casi unanimidad al opinar sobre la oportunidad de rescatar el texto cervantino para la escena de hoy, aunque no falte la voz disonante, en este caso de Jesús Vigorra desde Sevilla, que califica de "simpleza" y "pura anécdota" la trama de esta obra. En el extremo opuesto, y destacando valores específicos de la pieza, cabe recordar a Javier Villán, para quien los versos cervantinos son uun verdadero gozo".

4. Hay unanimidad, cuando se recuerda, en destacar la versión realizada por Luis Alberto de Cuenca. Remitimos al apartado dedicado a la «Adaptación del texto" para observar hasta dónde ha llegado el trabajo de Cuenca con el texto cervantino.

5. Parece haber acuerdo en la labor de los actores, sobre todo al destacar el excelente trabajo de Héctor Colomé en el papel de Madrigal, aunque ya hemos recogido la opinión que le merece a J. M. Padilla. Algún crítico reseña también muy negativamente la interpretación de Silvia Marso como Gran Sultana y, de nuevo, encontramos contradicciones: López Sancho recuerda con agrado a cuatro actores, y entre ellos, a José Lifante en el Gran

\footnotetext{
9 Nos referimos a los citados en nota 4.
} 
Cadí; ya hemos recordado que Padilla, por su parte, califica el trabajo de este actor como de «betuneron. Claro que este crítico dice inmediatamente que «los eunucos sacan la pelvis como cómicas locas...».

6. No falta la alusión a "los dineros" de la Compañía Nacional de Teatro Clásico, presupuesto que le viene como institución oficial de carácter público $\mathrm{y}$, por tanto, con los medios consiguientes para su funcionamiento. Ese recuerdo a los medios económicos de la CNTC lleva consigo una crítica evidente por parte de las personas que los recuerdan, al considerarlos un agravio comparativo con la penuria en que se encuentra, según esas personas, el teatro privado. Naturalmente, hay opiniones contrarias a ésta, pues mientras -otra vez- Padilla y Vigorra son absolutamente reticentes en el uso que de esos "dineros" se hace, Alberto de la Hera lo da por «muy bien empleado" en este caso.

En fin, como se puede apreciar, las conclusiones están en la misma línea que expusimos en trabajos anteriores sobre el tema. Sorprenden, de nuevo y fundamentalmente, las manifiestas discrepancias de algunos críticos, no sólo sobre el resultado general del espectáculo sino sobre aspectos muy concretos, en que las opiniones son totalmente opuestas...

\section{LA RECEPCIÓN POR PARTE DEL PÚBLICO}

Ofrecemos, a continuación, los datos numéricos absolutos y porcentuales correspondientes a los lugares en que La Gran Sultana se ha representado:

a) Esta comedia fue presenciada, en primer lugar y como hemos señalado por el público de Sevilla, representándose en el Teatro Lope de Vega durante cinco días. Teniendo en cuenta que el aforo de este local es de 723 localidades y que asistieron 3.615 personas, el índice de ocupación fue del 100 por 100.

b) La obra llegó a su sede madrileña del Teatro de la Comedia el 20 de septiembre de 1992 y estuvo ininterrumpidamente hasta el 13 de diciembre del mismo año. Fueron 73 funciones con 38.238 espectadores. El aforo del teatro es de 619 asientos, lo cual quiere decir que el índice de ocupación fue del 85 por 100.

c) Después del estreno de Fuenteovejuna, la Compañía dejó 
de representar la obra cervantina hasta que se repuso en el Mercat de les Flors de Barcelona (630 localidades) en marzo de 1993 con doce representaciones, 7.470 espectadores y un índice de ocupación del 98 por 100 .

d) Volvió en mayo al Teatro de la Comedia. Fueron 26 funciones, con 11.646 espectadores y un índice de ocupación del 73 por 100 .

e) Como es habitual, la CNTC se desplazó a Almagro en el mes de julio para participar en su Festival de teatro clásico, estrenando en este caso el nuevo espacio del Hospital de San Juan. Se dieron nueve representaciones, con 5.087 espectadores en un aforo de 600 localidades. El índice de ocupación fue del 94 por 100.

f) Durante el mes de septiembre, la Compañía realizó una gira por Galicia. Actuó, en primer lugar, en el Palacio de Congresos de La Coruña con dos representaciones y reuniendo 2.581 espectadores en un aforo de 1.400 butacas. Indice de ocupación: 92 por 100. En Santiago de Compostela se llevaron a cabo dos representaciones en el Auditorio de Galicia, asistiendo 1.327 espectadores. Dado que el aforo es de 764 localidades, el índice de ocupación fue del 87 por 100.

g) El mes de octubre La Gran Sultana se presentó en Méjico. En Guanajuato se puso en escena -Auditorio del Estado- en cuatro ocasiones, con 4.446 espectadores; el aforo del Auditorio es de 1.200 localidades $y$, en consecuencia, el índice de ocupación fue del 93 por 100. En la Ciudad de Méjico, Teatro Julio Castillo, se dieron cinco representaciones, con 2.855 espectadores. Aforo del teatro: 1.027 espacios. Indice, pues, de ocupacion: 56 por 100 .

h) Las últimas funciones de la comedia cervantina en España se dieron de nuevo en el Teatro de la Comedia de Madrid del 12 de noviembre de 1993 al 23 de enero de 1994. Fueron 61 funciones, 30.487 espectadores y un índice de ocupación del 81 por 100.

i) La Gran Sultana se desplazó a Londres, donde fue representada del 23 al 26 de marzo de 1994. Las funciones tuvieron lugar en el Sadler's Wells Theatre, con traducción al inglés por medio de una pantalla colocada en la parte superior central del escenario («surtitles»). Estas cuatro representaciones ${ }^{10}$, que se

10 Con motivo de la presentación de la obra en Londres, tuvo lugar también una mesa redonda en la Cancillería de la Embajada de España en esa ciudad, bajo el título $\approx$ La Gran Sultana de Miguel de Cervantes. Texto y puesta en escenax. Participaron Adolfo Marsillach, Paul Lewis Smith, Edwin Williamson y Luciano García Lorenzo. La organización del acto corrí a cargo del Instituto Cervantes en la capital inglesa, con la colaboración de la CNTC. 
enmarcaron en el "Spanish Arts Festival», celebrado durante los meses de enero y siguientes de 1994, contaron con una asistencia de 3.900 espectadores y un índice de ocupación de la sala (1.400 plazas) del 70 por 100 .

Este es el cuadro-resumen de las afirmaciones anteriores:

\section{LA GRAN SULTANA}

Del 6 al 12 de septiembre de 1992 (Sevilla: Teatro Lope de Vega).

\begin{tabular}{|c|c|c|c|}
\hline Aforo & $\begin{array}{l}\text { Número } \\
\text { de } \\
\text { funciones }\end{array}$ & $\begin{array}{c}\text { Número } \\
\text { de } \\
\text { especiadores }\end{array}$ & $\begin{array}{l}\text { Porcentaje } \\
\text { de } \\
\text { ocupación }\end{array}$ \\
\hline 723 & 5 & 3.615 & 100 \\
\hline
\end{tabular}

Del 20 de septiembre al 13 de diciembre de 1992 (Madrid: Teatro de la Comedia)

$$
619
$$

Del 16 al 28 de marzo de 1993 (Barcelona: Mercat de les Flors)

Del 1 al 30 de mayo de 1993 (Madrid: Teatro de la Comedia) ....

Del 2 al 11 de julio de 1993 (Almagro: Hospital de San Juan).

4 y 5 de septiembre de 1993 (La Coruna: Palacio de Congresos)

18 y 19 de septiembre de 1993 (Santiago de Compostela: Auditorio de Galicia)

14 al 17 de octubre de 1993 (Guanajuato: Auditorio del Estado)

22 al 27 de octubre de 1993 (México D. F.: Teatro Julio Castillo)

Del 12 de noviembre de 1993 al 23 de enero de 1994 (Madrid: Teatro de la Comedia).

Del 23 al 26 de marzo de 1994 (Londres: Theatre Sadler's Wells)

TOTAL

\begin{tabular}{rrrr}
630 & 12 & 7.470 & 98 \\
619 & 26 & 11.646 & 73 \\
600 & 9 & 5.087 & 94 \\
1.400 & 2 & 2.581 & 92 \\
764 & 2 & 1.327 & 87 \\
1.200 & 4 & 4.446 & 93 \\
1.027 & 5 & 2.855 & 56 \\
& & & 81 \\
619 & 61 & 30.487 & 81 \\
\hline 1.400 & 4 & 3.900 & 70 \\
\hline & 203 & 111.652 & 84
\end{tabular}


Las conclusiones principales de todos los datos expuestos en este apartado serían las siguientes:

1. El alto número de funciones: 203. Efectivamente, La Gran Sultana es la obra que más se ha representado de las puestas en escena por la CNTC. Recordemos que las dos anteriores, también con un buen número de representaciones en su haber, fueron El desdén con el desdén (134 funciones) y La verdad sospechosa, que llego en 114 ocasiones a los escenarios.

Destaca también que la mayor cantidad de representaciones corresponde a Madrid, lo cual es habitual, y que el número de las llevadas a cabo fuera de la sede del Teatro de la Comedia sigue siendo prácticamente el mismo que con las últimas obras de la CNTC. De La Gran Sultana se han hecho 43 representaciones fuera de Madrid, cuatro más que de El desdén... y una más que de La verdad sospechosa, pues fueron 42.

2. También el número de ciudades visitadas no difiere mucho de las obras inmediatas anteriores. La Gran Sultana se ha visto en ocho ciudades (dos americanas y una europea), además de en Madrid. El desdén... viajó a siete (tres en el extranjero) y La verdad... lo hizo a diez, aunque esta obra no salió fuera de España.

3. A tener en cuenta los índices de ocupación, muy altos en todas las ciudades, excepto en Méjico D. F. Destacan especialmente los indices de Sevilla (100 por 100), Barcelona ( 98 por 100), Almagro (94 por 100), etc., frente al de Ciudad de Méjico (56 por 100). A considerar la media de Madrid (82 por 100 en 160 representaciones), número éste no habitual en la cartelera madrileña y mucho menos, hasta hace poco tiempo, con una obra clásica. En fin, señalar el índice medio de ocupación teniendo en cuenta todas las ciudades y que ha sido del 84 por 100 , como asimismo el número total de espectadores: 111.652.

Hasta aquí las conclusiones que de unos datos objetivos y específicos hemos extraído. Una cosa es bien cierta: Cervantes ha llegado a escena con una obra que ocupaba lugar muy secundario en su producción dramática. Y ha llegado con una aceptación por parte del público que difícilmente era imaginable antes de ser vista y oída sobre las tablas...

LUCIANO GaRCta LORENZO

CSIC, Madrid 